\title{
Scrum and Temporal Distance-Based Global Software Development
}

\author{
Asmaa Fowzi Alotaibi, M. Rizwan Jameel Qureshi \\ Faculty of Computing and Information Technology, King Abdulaziz University, Jeddah, Saudi Arabia \\ Email: a.f.e.o@hotmail.com, anriz@ hotmail.com
}

\begin{abstract}
Global software development (GSD) is one of modern trends in software engineering. The last years has witnessed a significant increase in the adoption of Agile in GSD .This paper considers the issue by examining whether Scrum practices used in mitigation of temporal distance-based GSD coordination challenges. We were used Cisco TelePresence tool in Synchronization communication for simulation of face to face meetings. We were designed a simple algorithm to help project managers in determining the appropriate strategies. This algorithm is based on the temporal difference between the sites. This is may be great or simple. Through temporal difference, we calculated number of working hours overlapping. Which are classified in the three cases and each case has number of strategies are sufficient to overcome this challenges.
\end{abstract}

Index Terms - Global software development, challenge, scrum, coordination, temporal.

\section{INTRODUCTION}

Global software development (GSD) is one of modern trends in software engineering. This paradigm shift has significant benefits that can accrue. GSD is the development of software that is distributed in the two or more locations. These sites are located in different time zones. There are many challenges associated with GSD like geographic, social, cultural and temporal. In contrast, GSD have a lot of benefits like organization can access to qualified and skilled employees with lower cost and saving localized resources.

Agile software development has gained too much interest in last several years due to its flexible approach towards managing requirements, fostering of close collaboration between developers and customers, and frequent and early and reduced risks about failure of software. Agile methods are proposed assuming colocated development teams while GSD assumes distributed teams. Practitioners are adapting agile practices to GSD to take advantages of both methods. Scrum method is gaining more attention and it is extensively practiced in GSD projects as compared to the other agile methods [1].

Scrum is an iterative and incremental project management approach that provides a simple "inspect and adapt" framework. In Scrum, software is delivered in increments called sprints (usually 2 - 4 weeks iteration).
Each sprint starts with planning and ends with a review. A sprint planning by a Scrum team is a time-boxed meeting that could last up to 4 hours. It is dedicated to design planning for next sprint. The stakeholders of a project attend sprint review meetings to review the state of business, market and technology. These meetings could also last up to 4 hours. A retrospective meeting may be scheduled to assess teamwork after completing sprints. A daily Scrum meeting is fifteen minutes long and each team member addresses three questions: 1) what did I do yesterday? 2) what will I do today? 3) what impediments are on my way?. Scrum produces three artifacts namely: product backlogs, sprint backlogs and burn-down charts. Backlogs contain customer requirements and daily burn down charts shows the cumulative work remaining [2].

Distribution in GSD offers set of challenges for communication, control and coordination of development process like temporal, geographical, and socio-cultural. This study focuses on examining the use of Scrum practices to mitigate GSD coordination challenges.

The remainder of this paper is organized as follows. Section II overviews the related work. Section III describes the research problem and the proposed solution. Validation of the proposed solution is covered in section IV.

\section{RELATED WORKS}

Ten values are described as a list for a person who has to lead an agile team [3]. However, this list in not exhaustive and encourages readers to define their own list. The main focus is on integrity, relations, scope and need, seamlessly foster learning, authority, people, encouragement; fair play with customer, in-time delivery and team building [3]. The underlying theoretical foundations, reviews and classification of agile model driven development (AMDD) are covered and a comparison of existing AMDD processes is provided [4]. The results indicate significant disparity between compared processes to take inference that the AMDD concepts are still in their infancy. AMDD processes adopt a diversity of methods and paradigms, and show no sign of convergence among themselves. It is described that how Scrum can be taught to cover basic concepts of project management without necessitating revision of the syllabus [5]. This strategy increases the motivation and interest level of students due to adoption of this approach. 
The results indicate that Scrum method is adaptable to a situation other than the software development [5]. It is discussed how to determine an impact on software quality by adopting a formal process using a case study of a

Table 1: Comparison of Related Work

\begin{tabular}{|c|c|}
\hline Paper Title and Reference Number & Limitations \\
\hline $\begin{array}{l}\text { Agile Project Leadership - My Top } 10 \text { Value } \\
\text { Driven Principles [3] }\end{array}$ & The list of values in not exhaustive and encourages audience to define their own list. \\
\hline $\begin{array}{l}\text { Agile Model Driven Development: An } \\
\text { Intelligent Compromise [4] }\end{array}$ & $\begin{array}{l}\text { The results indicate significant disparity between compared processes that implies the AMDD } \\
\text { concepts are still in their infancy. AMDD processes adopt a diversity of methods and paradigms, } \\
\text { and show no sign of convergence among themselves. Lack of academic research in this area. }\end{array}$ \\
\hline $\begin{array}{l}\text { Using Scrum for Software Engineering Class } \\
\text { Projects [5] }\end{array}$ & $\begin{array}{l}\text { This study cannot accommodate more sprints. That will enable us to measure the velocity } \\
\text { properly. Also this study is need to introduce the additional Scrum techniques such as } \\
\text { retrospectives and to manage the Scrum roles much more effectively }\end{array}$ \\
\hline $\begin{array}{l}\text { A Case Study Analyzing the Impact of } \\
\text { Software Process Adoption on Software } \\
\text { Quality [6] }\end{array}$ & $\begin{array}{l}\text { This study need to consider at other quality indicators such as defect density, defect removal } \\
\text { efficiency in the future. }\end{array}$ \\
\hline $\begin{array}{l}\text { Improving agility and discipline of software } \\
\text { [7] }\end{array}$ & $\begin{array}{l}3.5 \% \text { were rejected and } 24.5 \% \text { of suggestions were evaluated as not applicable for organizational } \\
\text { or economic reasons, which leaves room for further improvement. }\end{array}$ \\
\hline $\begin{array}{l}\text { Driving Quality Improvement and Reducing } \\
\text { Technical Debt with the Definition of Done } \\
\text { [8] }\end{array}$ & $\begin{array}{l}\text { They do not yet have enough data to reach solid conclusions about improvements in non- } \\
\text { functional requirement. }\end{array}$ \\
\hline $\begin{array}{l}\text { Agile Practices in a Small-Scale, Time- } \\
\text { Intensive Web Development Project [9] }\end{array}$ & $\begin{array}{l}\text { In project was developed software product within the limited time frame; the product would have } \\
\text { been completed with fewer features or less quality otherwise. }\end{array}$ \\
\hline $\begin{array}{l}\text { ScrumTutor: A Web-based Interactive } \\
\text { Tutorial For Scrum Software Development } \\
{[10]}\end{array}$ & $\begin{array}{l}\text { The user can't plays the role of a 'team member', therefore the user not gets to be part of the } \\
\text { software team and contributes as a developer. }\end{array}$ \\
\hline $\begin{array}{l}\text { On the Difficulties for Students to Adhere to } \\
\text { Scrum on Global Software Development } \\
\text { Projects: Preliminary Results [11] }\end{array}$ & $\begin{array}{l}\text { The teams faced numerous difficulties to adhere to Scrum, they felt they learned a lot about this } \\
\text { type of process and had a good experience but the product was not completely ready. }\end{array}$ \\
\hline $\begin{array}{l}\text { Scrum Practice Mitigation of Global } \\
\text { Software Development Coordination } \\
\text { Challenges: A Distinctive Advantage? [12] }\end{array}$ & $\begin{array}{l}\text { First, only four of the twelve GSD challenges identified from the literature were examined. Others } \\
\text { remain to be investigated. Also, other GSD challenges may exist in practice that has not yet been } \\
\text { identified in the literature. Second, the study focused on the Scrum practices, rather than the tools } \\
\text { and mechanisms that mediate the challenge mitigation. Third, the study did not directly compare } \\
\text { Scrum practices with traditional development methods in mitigating these coordination } \\
\text { challenges. Rather, it chose projects in which project managers were seeking to gain benefits from } \\
\text { the use of Agile/Scrum over the previous traditional methods that they had used. Fourth, project } \\
\text { contextual factors were found to influence how Scrum was tailored to fit the project context. The } \\
\text { influence of these factors was not directly controlled or systematically examined in this study. } \\
\text { Finally, as implied above, further validation is needed, from other case studies and other research } \\
\text { methods, to further substantiate the conclusions. }\end{array}$ \\
\hline
\end{tabular}

Software company of Pakistan that is specialized in developing applications for the prepaid card industry [6]. Three different quality indicators are used for this purpose: error severity; defect severity; and P/F. The data related to these three indicators are obtained and analyzed at two different stages: 1) no formal process stage and 2) agile stage. The results indicate that by adopting a formal agile Scrum process in the case study contributes to improve software quality not only reducing the percentage of high severity errors and defects but also increasing the $\mathrm{P} / \mathrm{F}$ ratio. Defect density and defect removal efficiency quality indicators are not considered to conclude the results [6].

CMMI-Scrum reference model is proposed by integrating Scrum methodology with the Capability Maturity Model Integration (CMMI) model to improve both agility and discipline in software development [7]. The results show that the proposed CMMI-Scrum model is capable of supporting organizations with different levels of maturity and agility [7]. Experiences of using Scrum are described to drive quality improvements and quantitative results are very encouraging [8]. A case study is presented on agile practices in a small-scale web development project [9]. The study reports that agile practices are successfully implemented confirming that agile methodologies are suitable for voluntary, selforganized, cross-functional teams for small projects [9].

A project 'ScrumTutor' is presented with an aim to provide learning experience of Scrum [10]. It is designed and developed for undergraduate students in introductory course of software engineering. A user cannot play the role of a 'team member' using 'ScrumTutor'. Global software development project is presented [11]. Developers are distributed across three countries to develop mobile solutions on the theme of sustainability. Scrum process and IBM Rational Team Concert tool are used [11]. The results show that the developers in a distributed environment and tool have a profound effect on adherence to Scrum. Scrum is a demanding process for developers and it maintains the artifacts. The teams faced numerous difficulties in adherence to Scrum. Most of the team members reported that they learned a lot about distributed implementation of Scrum and it was a new and good experience [11].

An empirical study is described about the usage of Scrum practices in GSD, and what are the main coordination challenges [12]. It is found that Scrum offers distinctive advantages in mitigating geographical and socio-cultural challenges but not effective for temporal distance-based GSD coordination challenge [12] such as 
Scrum implementation requires long meetings (e.g. planning meeting is four hours) and communication among distributed teams is a problematic issue . Table 1 summarized the related work.

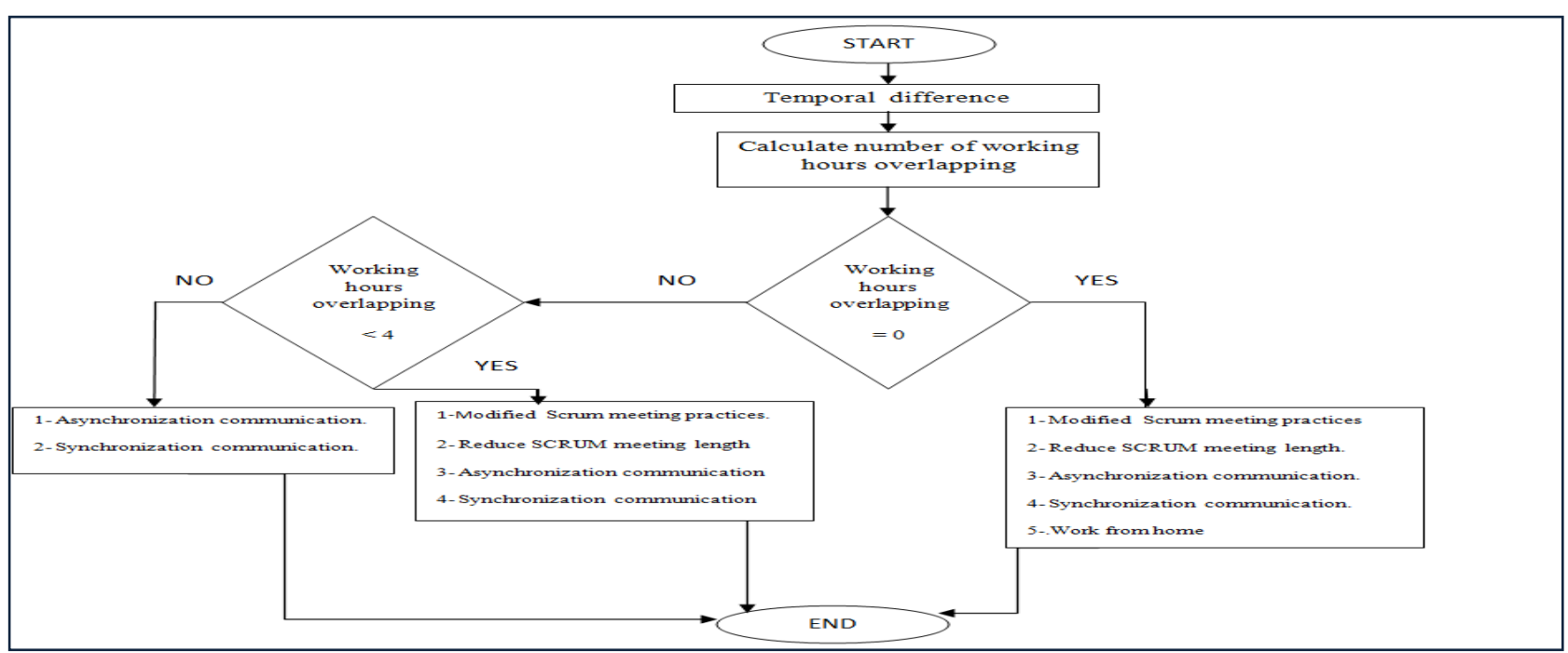

Fig 1: The Proposed Algorithm to solve problems in GSD Environment

\section{PROBlem DEFINITION AND THE PROPOSED SOLUTION}

Scrum implementation is a problem for global software development projects. Some of these challenges or problems are due to temporal difference between sites. This research aims to address the temporal distance-based GSD coordination challenge.

The proposed solution, of the temporal problem in a GSD environment, is as follows.

\section{Common strategies}

There are several strategies used with scrum to mitigate the impact of temporal distance-based coordination challenges.

\section{Synchronized working hours}

This strategy is used to synchronize working hours between distributed sites to support SCRUM meeting. This strategy provides good environment to communicate with the help of many communication tools. The Scrum team must choose the appropriate tool from a set of tools. Communication channel must have large bandwidth, high degree of reliability and high performance specifications.

\section{Cisco TelePresence}

Cisco provides video conferencing technology. It can override barriers and facilitate remote meetings. This technique improves the availability of team members and efficiency of a team to a large extent.

\section{Other tools}

Use phone, web camera, teleconference, net meeting, email, shared mailing list, IM, Short Message Service (SMS) and internet relay chat (IRC). This strategy is used with tools to facilitate synchronous communication and messaging between members of team for example emails and instant messaging.

\section{Reduce SCRUM meeting length}

This strategy is used to make a meeting short (e.g. fourth minute Scrum planning meetings). Scrum methodology is flexible and allows adaptability to avoid work during the night or work for long hours.

Following are the guidelines to reduce meeting times using Scrum in GSD environment.

- Convert daily Scrum meeting to twice a week meetings.

- Scrum teams should emphasis on effective communication policy to avoid delay (e.g. replies an email within 12 hours).

- Synchronous retrospective meetings (e.g., posting results and comments on Wikis).

Fig. 1 shows the proposed algorithm to help project managers in determining the appropriate strategy to solve temporal difference between sites. Through temporal difference, we can calculate number of working hours overlapping. Which are classified in the three cases and each case has number of strategies.

First case: No any overlapping work hours.

This is the most difficult situation that may face the scrum in global software development. Where there are no hours are shared between sites. This requires confronting the difficulties this situation with the implementation of set of strategies.

These include the status of the following strategies:

1. Meeting Scrum practices modified.

2. SCRUM reduces the length of the meeting.

3. Asynchronization communication.

4. Synchronization communication by Cisco TelePresence.

5. Work from home. 
Second case: Number of working hours overlapping (Less than 4)

This condition occurs when there are low numbers of synchronous working hours between distributed sites.

1. Asynchronization communication.

(More than 4 or equal to 4 ).

2. Synchronization communication by Cisco TelePresence.

Third case: Number of working hours overlapping.

\section{VALIDATION OF THE PROPOSED SOLUTION}

A survey is conducted to validation the proposed solution using an electronic survey. Questionnaire is composed of eighteen questions. The results of survey are presented in the form of frequency tables. Tables 3 to 20 show that respondents have high support for the proposed solution. Table 2 shows likert scale ranging from 1 to 5 .

Table 2: Likert Scale

\begin{tabular}{|l|l|}
\hline 1 & Very Low \\
\hline 2 & Low \\
\hline 3 & Nominal \\
\hline 4 & High \\
\hline 5 & Very High \\
\hline
\end{tabular}

Q1: Can we use scrum in mitigation of temporal distancebased GSD coordination challenge?

Table 3: Result for Question 1

\begin{tabular}{|l|l|l|}
\hline Likert Scale & Frequency & Percent \\
\hline 1 & 2 & 6.45 \\
\hline 2 & 1 & 3.23 \\
\hline 3 & 12 & 38.71 \\
\hline 4 & 13 & 41.94 \\
\hline 5 & 3 & 9.86 \\
\hline
\end{tabular}

Q2: Can we say that scrum will succeed in mitigation of this challenge?

Table 4: Result for Question 2

\begin{tabular}{|l|l|l|}
\hline Likert Scale & Frequency & Percent \\
\hline 1 & & \\
\hline 2 & 4 & 12.90 \\
\hline 3 & 11 & 35.48 \\
\hline 4 & 11 & 35.48 \\
\hline 5 & 5 & 16.13 \\
\hline
\end{tabular}

Q3: Do you agree that the strategies are sufficient to overcome this challenge?

Table 5: Result for Question 3

\begin{tabular}{|l|l|l|}
\hline Likert Scale & Frequency & Percent \\
\hline 1 & & \\
\hline 2 & 2 & 9.68 \\
\hline 3 & 9 & 29.03 \\
\hline 4 & 17 & 54.84 \\
\hline 5 & 3 & 9.68 \\
\hline
\end{tabular}

Q4: we Do you think that the algorithm will help in determining of appropriate strategies?
Table 6: Result for Question 4

\begin{tabular}{|l|l|l|}
\hline Likert Scale & Frequency & Percent \\
\hline 1 & & \\
\hline 2 & 2 & 6.45 \\
\hline 3 & 7 & 22.58 \\
\hline 4 & 20 & 64.52 \\
\hline 5 & 2 & 6.45 \\
\hline
\end{tabular}

Q5: Do you agree that synchronized working hours must be used as first step in all cases?

Table 7: Result for Question 5

\begin{tabular}{|l|l|l|}
\hline Likert Scale & Frequency & Percent \\
\hline 1 & & \\
\hline 2 & 1 & 3.23 \\
\hline 3 & 10 & 32.26 \\
\hline 4 & 16 & 51.61 \\
\hline 5 & 4 & 12.90 \\
\hline
\end{tabular}

Q6: Do you think that classification of cases in this algorithm is perfect?

Table 8: Result for Question 6

\begin{tabular}{|l|l|l|}
\hline Likert Scale & Frequency & Percent \\
\hline 1 & & \\
\hline 2 & 1 & 3.23 \\
\hline 3 & 9 & 29.03 \\
\hline 4 & 17 & 54.84 \\
\hline 5 & 4 & 12.90 \\
\hline
\end{tabular}

Q7: Can we say that algorithm will succeed in mitigation of this challenge?

Table 9: Result for Question 7

\begin{tabular}{|l|l|l|}
\hline Likert Scale & Frequency & Percent \\
\hline 1 & & \\
\hline 2 & 3 & 9.68 \\
\hline 3 & 9 & 29.03 \\
\hline 4 & 15 & 48.39 \\
\hline 5 & 4 & 12.90 \\
\hline
\end{tabular}

Q8: Do you think that the proposed solution will help of projects managers in determining of appropriate strategies?

Table 10. Result for Question 8

\begin{tabular}{|l|l|l|}
\hline Likert Scale & Frequency & Percent \\
\hline 1 & 1 & 3.23 \\
\hline 2 & 1 & 3.23 \\
\hline 3 & 9 & 29.03 \\
\hline 4 & 16 & 51.61 \\
\hline 5 & 4 & 12.90 \\
\hline
\end{tabular}

Q9: Can we say that dependence on temporal difference will make easy to choosing of strategies?

Table 11: Result for Question 9

\begin{tabular}{|l|l|l|}
\hline Likert Scale & Frequency & Percent \\
\hline 1 & & \\
\hline 2 & 1 & 3.23 \\
\hline 3 & 11 & 35.48 \\
\hline 4 & 16 & 51.61 \\
\hline 5 & 3 & 9.68 \\
\hline
\end{tabular}


Q10: How much is it suitable to use cisco-telepresence in synchronization communication?

Table 12: Result for Question 10

\begin{tabular}{|l|l|l|}
\hline Likert Scale & Frequency & Percent \\
\hline 1 & & \\
\hline 2 & 2 & 6.45 \\
\hline 3 & 10 & 32.26 \\
\hline 4 & 15 & 48.39 \\
\hline 5 & 4 & 12.90 \\
\hline
\end{tabular}

Q11: Can do you agree that flexibility of scrum helps to overcome this challenge?

Table 13: Result for Question 11

\begin{tabular}{|l|l|l|}
\hline Likert Scale & Frequency & Percent \\
\hline 1 & 1 & 3.23 \\
\hline 2 & 1 & 3.23 \\
\hline 3 & 9 & 29.03 \\
\hline 4 & 16 & 51.61 \\
\hline 5 & 4 & 12.90 \\
\hline
\end{tabular}

Q12: Do you think that classification of strategies based on temporal differences is right?

Table 14: Result for Question 12

\begin{tabular}{|l|l|l|}
\hline Likert Scale & Frequency & Percent \\
\hline 1 & 1 & 3.23 \\
\hline 2 & 2 & 6.45 \\
\hline 3 & 10 & 32.26 \\
\hline 4 & 14 & 45.16 \\
\hline 5 & 4 & 12.90 \\
\hline
\end{tabular}

Q13: Do you think that the synchronization communication with Cisco TelePresence will be able to simulation of face to face meetings?

Table 15: Result for Question 13

\begin{tabular}{|l|l|l|}
\hline Likert Scale & Frequency & Percent \\
\hline 1 & & \\
\hline 2 & 2 & 6.45 \\
\hline 3 & 10 & 32.26 \\
\hline 4 & 16 & 51.61 \\
\hline 5 & 3 & 9.68 \\
\hline
\end{tabular}

Q14: Do you agree for the use of synchronization communication strategy in all cases?

Table 16: Result for Question 14

\begin{tabular}{|l|l|l|}
\hline Likert Scale & Frequency & Percent \\
\hline 1 & & \\
\hline 2 & 3 & 9.68 \\
\hline 3 & 11 & 35.48 \\
\hline 4 & 13 & 41.94 \\
\hline 5 & 4 & 12.90 \\
\hline
\end{tabular}

Q15: Do you agree for the use of work from home strategy in case that joint working hours is zero?
Table 17: Result for Question 15

\begin{tabular}{|l|l|l|}
\hline Likert Scale & Frequency & Percent \\
\hline 1 & & \\
\hline 2 & 5 & 16.13 \\
\hline 3 & 12 & 38.71 \\
\hline 4 & 12 & 38.71 \\
\hline 5 & 2 & 6.45 \\
\hline
\end{tabular}

Q16: Do you agree for the use of Reduce SCRUM meeting length strategy in the case of overlapping work hours were few or zero?

Table 18: Result for Question 16

\begin{tabular}{|l|l|l|}
\hline Likert Scale & Frequency & Percent \\
\hline 1 & & \\
\hline 2 & 1 & 3.23 \\
\hline 3 & 13 & 41.94 \\
\hline 4 & 14 & 45.16 \\
\hline 5 & 3 & 9.68 \\
\hline
\end{tabular}

Q17: Do you agree for the use of synchronization communication strategy in all cases?

Table 19: Result for Question 17

\begin{tabular}{|l|l|l|}
\hline Likert Scale & Frequency & Percent \\
\hline 1 & & \\
\hline 2 & 4 & 12.90 \\
\hline 3 & 9 & 29.03 \\
\hline 4 & 15 & 48.39 \\
\hline 5 & 3 & 9.68 \\
\hline
\end{tabular}

Q18: Do you agree for the use of modified Scrum meeting practices strategy in the case of overlapping work hours were few or zero?

Table 20: Result for Question 18

\begin{tabular}{|c|c|c|}
\hline Likert Scale & Frequency & Percent \\
\hline 1 & & \\
\hline 2 & 1 & 3.23 \\
\hline 3 & 10 & 32.36 \\
\hline 4 & 17 & 54.84 \\
\hline 5 & 3 & 10.14 \\
\hline
\end{tabular}

\section{CONCLUSION AND FUTURE WORK}

We proposed an algorithm to adapt SCRUM practices to mitigate temporal distance-based GSD coordination challenge. Few strategies are discussed to mitigate the coordination challenges between distributed teams. The proposed algorithm is classified on the basis of the number of hours of work shared between sites. It will help Scrum teams in the identification and selection of appropriate strategies. The future work is to conduct further research to implement the proposed algorithm using case studies to generalize the results for the development of distributed projects. 


\section{REFERENCES}

[1] P. Bannerman, E. Hossain and R. Jeffery. Scrum Practices in Global Software Development: A Research Framework In Proceedings of the International Conference on Product Focused Development and Process Improvement, 2011.

[2] E.Hossain, M. Babar, H. Paik and J.Verner. Risk Identification and Mitigation Processes for Using Scrum in Global Software Development: A Conceptual Framework. In 6th Asia-Pacific Software Engineering Conference, 2009.

[3] Lynne Ralston. Agile Project Leadership - My Top 10 Value Driven Principles. In Agile Conference, 2008.

[4] Reza Matinnejad. Agile Model Driven Development: An Intelligent Compromise. In Ninth International Conference on Software Engineering Research, Management and Applications, 2011.

[5] Ramrao Wagh. Using Scrum for Software Engineering Class Projects. In Agile India, 2012.

[6] R.Tufail and A. Malik. A Case Study Analyzing the Impact of Software Process Adoption on Software Quality. In 10th International Conference on Frontiers of Information Technology, 2012.

[7] K. Lukasiewicz and J. Miler. Improving agility and discipline of software development with the Scrum and CMMI. In IET Software, February 2012.

[8] Noopur Davis. Driving Quality Improvement and Reducing Technical Debt with the Definition of Done. In Agile Conference, 2013.

[9] X.Zhang and B.Dorn. Agile Practices in a Small-Scale, Time-Intensive Web Development Project. In Eighth
International Conference on Information Technology: New Generations, 2011.

[10] S.Potineni, S.Bansal and A.Amresh. ScrumTutor: A Webbased Interactive Tutorial for Scrum Software Development. In International IEEE Conference, 2013.

[11] Scharff, S. Heng and V. Kulkarni. On the Difficulties for Students to Adhere to Scrum on Global Software Development Projects: Preliminary Results. In International IEEE Conference, 2012.

[12] P.Bannerman, E.Hossain and R. Jeffery. Scrum Practice Mitigation of Global Software Development Coordination Challenges: A Distinctive Advantage? .In 45th Hawaii International Conference on System Sciences, 2012.

Asmaa Fowzi Alotaibi, Graduate Student of Information Technology, Faculty of Computing \& Information Technology, and King Abdulaziz University, major in Information Technology Management.

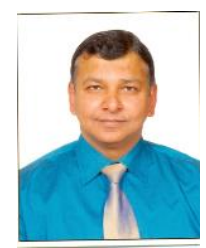

Dr. M. Rizwan Jameel Qureshi received his $\mathrm{Ph} . \mathrm{D}$ degree from National College of Business Administration \& Economics, Pakistan 2009. This author is best researcher awardees from Department of Information Technology, King Abdulaziz University Saudi Arabia in 2013 and Department of Computer Science, COMSATS Institute of Information Technology Pakistan in 2008.

How to cite this paper: Asmaa Fowzi Alotaibi, M. Rizwan Jameel Qureshi,"Scrum and Temporal Distance-Based Global Software Development", IJCNIS, vol.6, no.6, pp.48-53, 2014. DOI: 10.5815/ijcnis.2014.06.07 